\title{
AN ELECTROSTATIC, ON/OFF MEMS VALVE FOR GAS FUEL DELIVERY OF A MICROENGINE
}

\author{
Xue'en Yang, Alexander Hölke, and Martin Schmidt \\ Microsystems Technology Laboratories \\ Massachusetts Institute of Technology \\ Cambridge, MA 02139
}

\begin{abstract}
An electrostatic, on/off silicon valve designed to control gaseous fuel combustion by an array of such valves in a micro gas turbine engine was fabricated and fully characterized. Tested with nitrogen under room temperature, the valve opened against 10 atmospheres of pressure at $136 \mathrm{~V}$ and delivered a flow rate of 45 $\mathrm{sccm}\left(\mathrm{cm}^{3} / \mathrm{min}\right)$. At the same pressure, the helium leak-rate was expected to be less than $0.03 \mathrm{sccm}, 0.07 \%$ of the open flow rate. The valve showed no sign of failure after more than $10^{5}$ cycles.
\end{abstract}

\section{INTRODUCTION}

MIT is developing a MEMS gas turbine generator for high power density output in applications such as portable power sources and micro air vehicles [1]. Figure 1 shows the crosssectional view of the microengine in a 5-wafer stack. The valve is to be place on top of the fuel manifold, modulating the fuel flow from the tank to the combustion chamber. Table 1 lists the design specifications for the engine valve. In addition, during fabrication, the valve needs to survive wafer-bond anneals at $1100^{\circ} \mathrm{C}$, and during operation, it needs to open against 10 atm upstream pressure under a high-temperature operating environment $\left(400^{\circ} \mathrm{C}\right)$, and deliver a maximum flow rate of $600 \mathrm{sccm}$. Engine proportional flow control can be accomplished with an array of valves (designed to have 20 elements). However, the operation requirements cannot be met by previously reported MEMS valves, many of which are designed for lower-temperature, lower-pressure or lower-flow rate applications, e.g., by thermal [2], electromagnetic [3], or piezoelectric [4] actuations. Reported electrostatic valves did not meet the specifications because they used metals for actuation [5], used soft material for sealing surface [6], designed for low-pressure flow control [7], or designed for normally-open flow control [8].

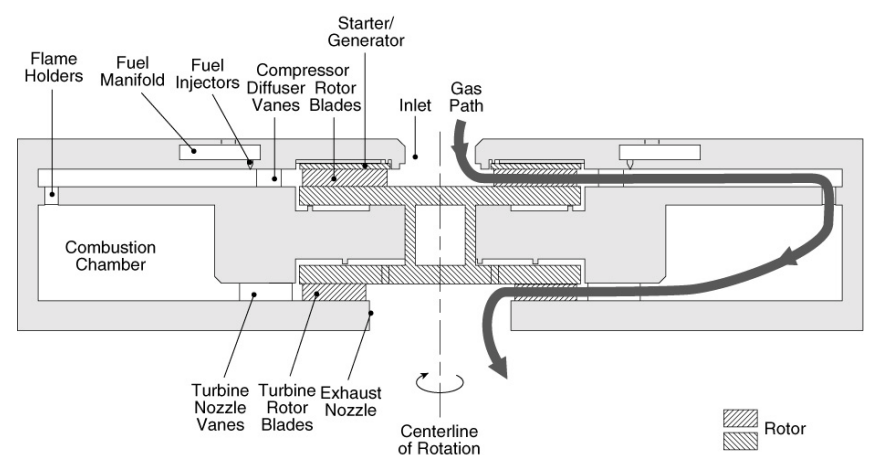

Figure 1. Cross-sectional view of the microengine. The fuel valve structure will be placed on top of the stack, between a fuel tank and the supply plenum.
Table 1. Fuel Valve Specifications for the microengine.

\begin{tabular}{|l||l|}
\hline \multicolumn{1}{|l||}{} & \multicolumn{1}{c|}{ Fuel Valve } \\
\hline \hline Fuel & Gaseous \\
\hline Temperature & $0^{\circ} \mathrm{C}-400^{\circ} \mathrm{C}$ \\
\hline Flow Rate (maximum) & $45 \mathrm{~g} / \mathrm{h}(600 \mathrm{sccm})$ \\
\hline Flow Rate (one valve) & $1.5 \mathrm{~g} / \mathrm{h}(30 \mathrm{sccm})$ \\
\hline Fuel Pressure & $1 \mathrm{Mpa}(10 \mathrm{~atm})$ \\
\hline Allowed Pressure Loss & $0.7 \mathrm{Mpa}(7 \mathrm{~atm})$ \\
\hline Leak Rate & $<0.03 \mathrm{~cm}^{3} / \mathrm{min} \mathrm{He}$ \\
\hline Power Consumption & $<10 \mathrm{~mW}$ \\
\hline Time Response & $10^{-1} \mathrm{~s}$ \\
\hline Size & $2.5 \mathrm{~cm}$ \\
\hline
\end{tabular}

\section{DESIGN AND FABRICATION}

Using fusion bonding of multiple Silicon-On-Insulator (SOI) wafers and Deep Reactive Ion Etch (DRIE), we were able to design and fabricate an electrostatic valve that demonstrated feasibility at room temperature. The prototype valve is comprised of three fusion-bonded wafers. Figure 2 shows the design concept using a 3-D bisected schematic. The valve is normally closed when the tank is pressurized. When voltage is applied between the top electrode and the boss, electrostatic force lifts up the boss and opens the valve, allowing gas fuel to flow past the top wafer and the tethers, then radially inward through the valve seat, and finally exit through the bottom of the die. The flow was designed to choke at the exit of the valve seat.
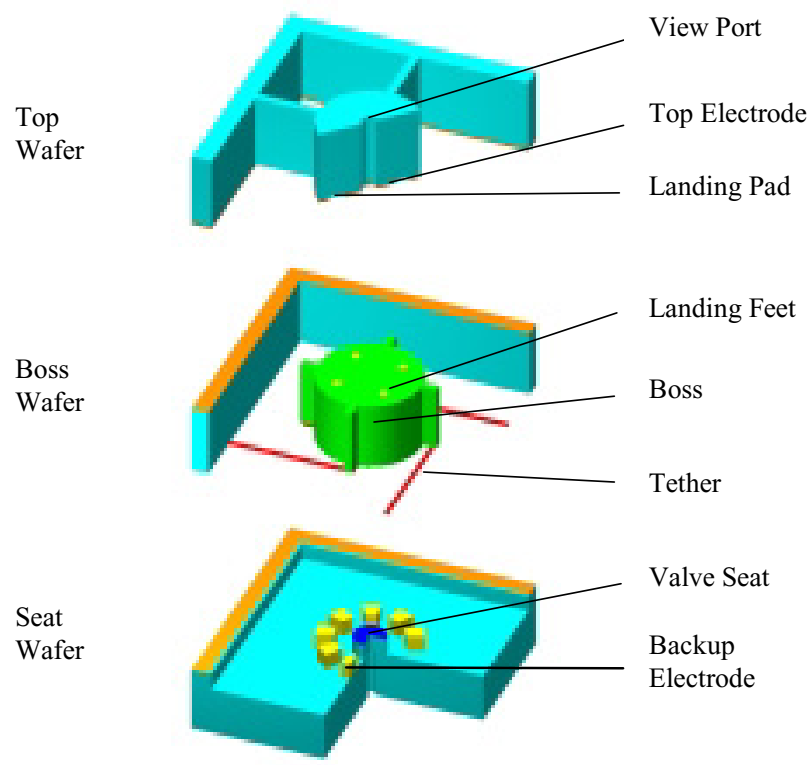

Figure 2. 3-D cross-sectional schematic of the micro valve.

Travel support has been generously provided by the Transducers Research Foundation and by the DARPA MEMS and DARPA bioflips programs 
A 2-D schematic of the three bonded layers is shown in Figure 3. As seen from the figure, the top wafer is prepared from a SOI wafer and it contains the view-port (for testing purpose), the top electrode and the landing pads. The top electrode is etched on a SOI layer, and the buried oxide layer is used as the insulation from the substrate, which is grounded during operation. The landing pads are cylindrical openings etched through the SOI and oxide layers. They are used as mechanical stops to prevent the boss from colliding on the top electrode during opening. The boss wafer, also prepared from a SOI wafer, features a silicon boss actuator supported on four straight tethers in a pinwheel configuration. The tethers are etched from a SOI layer to ensure uniform thickness. During operation, the tethers are grounded, and as a result, the boss is electrically floating. However, because of the dominant capacitance distribution in the buried oxide, the voltage drop between the boss and the tethers is not significant. During pull-in, the landing feet on top of the boss will move up and stop at the landing pads and thus make electrical contact with the grounded top substrate. By doing so, a minimum air gap is formed between the two electrodes and electric shorting is avoided. The bottom wafer, prepared from a double-sided polished (DSP) wafer, has the valve outlet, the valve seat and the backup electrode (used for testing purpose). The valve seat contains a polysilicon surface, which prevents bonding to the boss under high temperature contact because of its roughness.

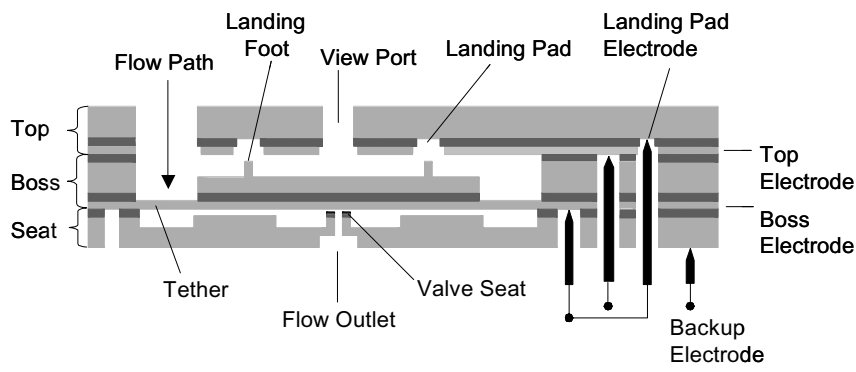

Figure 3. Schematic cross-section of the fuel valve.

A brief description of the fabrication sequences is as

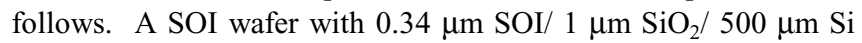
substrate thickness was used as the top wafer. The SOI layer was first plasma etched to define the top electrode area $(1.1 \mathrm{~mm}$ diameter) as well as the landing pad, and the oxide layer was HF etched using a different mask to avoid undercut. The wafer was then DRIE etched through from the bottom to form the inlet paths. The boss wafer used a SOI wafer with $17 \mu \mathrm{m} \mathrm{SOI} / 0.4 \mu \mathrm{m} \mathrm{SiO}{ }_{2} /$ $380 \mu \mathrm{m}$ Si substrate thickness. The wafer was first oxidized to form a $1.5 \mu \mathrm{m}$ thick oxide. Four landing feet, targeted for $3.4 \mu \mathrm{m}$ deep, were then plasma etched on the electrode area. Subsequently, the wafer was flipped and etched from the back using DRIE to form the $17 \mu \mathrm{m}$ thick, $60 \mu \mathrm{m}$ wide, and $800 \mu \mathrm{m}$ long tethers. DRIE was then used again to etch from the top, using the buried oxide as the etch stop. Finally, the boss was released using an ultrasonic HF bath to etch away the oxide layer. Fabrication of the seat wafer was a little more complicated. A DSP wafer was first oxidized (for $0.7 \mu \mathrm{m}$ thick). $0.95 \mu \mathrm{m}$ of LPCVD polysilicon was then deposited at $625 \mathrm{C}$ (as the valve seat). The wafer was subsequently oxidized again (for $1 \mu \mathrm{m}$ thick). After a series of DRIE etches, a flow channel of inner diameter $36 \mu \mathrm{m}$ and $200 \mu \mathrm{m}$ depth connected to an outlet of $100 \mu \mathrm{m}$ diameter and 250 $\mu \mathrm{m}$ depth was formed. The valve seats were flat and two geometries were used: diameter 34 and $42 \mu \mathrm{m}$, on a total of six dies. After the three wafers were fabricated, they were fusion bonded together and annealed at $1100 \mathrm{C}$ for 1 hour. The wafer stack was then die-sawed into $1.54 \mathrm{~cm} \times 1.54 \mathrm{~cm}$ square chips. Figure 4 shows the SEM photos of the three wafers as fabricated as well as the pictures of the valve chip.

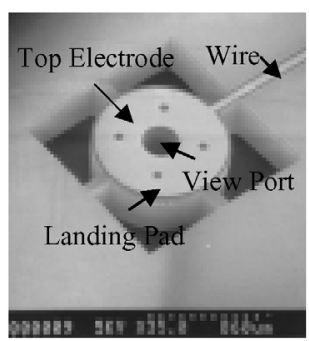

Top Wafer

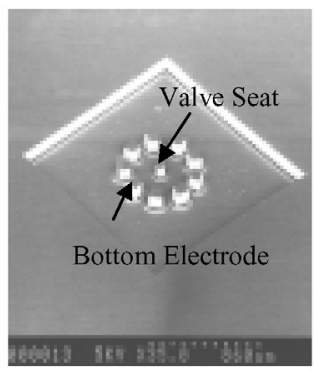

Seat Wafer

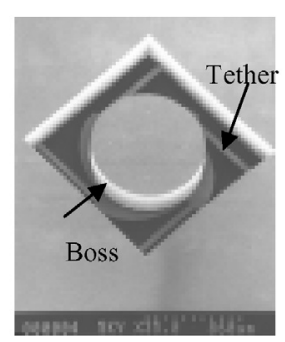

Boss Wafer

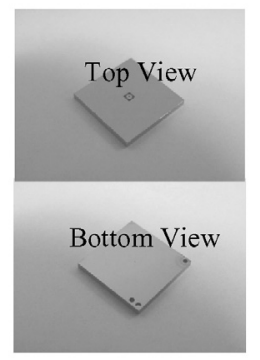

Valve Chip
Figure 4. SEM photos of the three wafers as fabricated, as well as pictures of valve chip.

\section{PACKAGING AND EXPERIMENTAL SETUP}

The prototype valve was tested under room temperature using nitrogen. The package for the fuel valve was designed to withstand at least $10 \mathrm{~atm}$ and support a maximum voltage of $300 \mathrm{~V}$. We used plexiglass for the flow housing, and pogo pins for electrical connection. Figure 5 shows the package assembly. The valve chip is placed at the center of the aluminum spacer. Fluid connection is achieved by fitting Scanivalve stainless steel tubes into the side openings of the top and bottom plates and sealing them with epoxy. Pogo pins are fixed into the pinholes of the pin holder, delivering electrical potentials from a voltage source to the different layers of the valve chip.

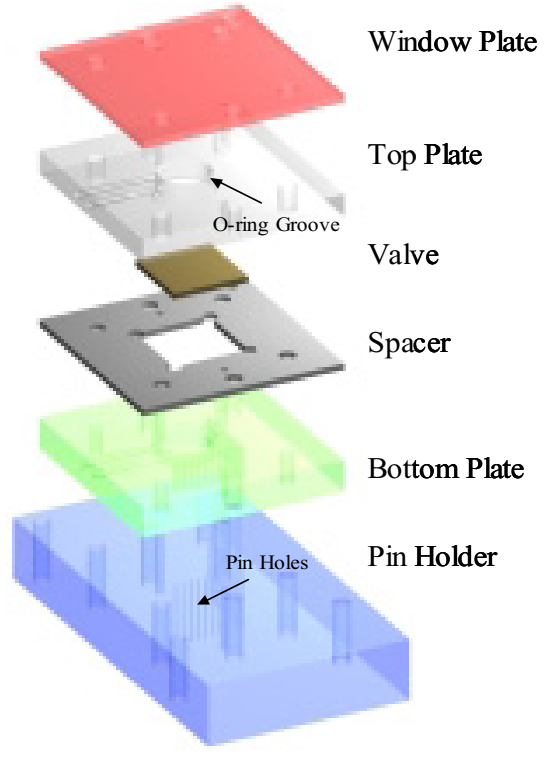

Figure 5. Package assembly for valve testing. 


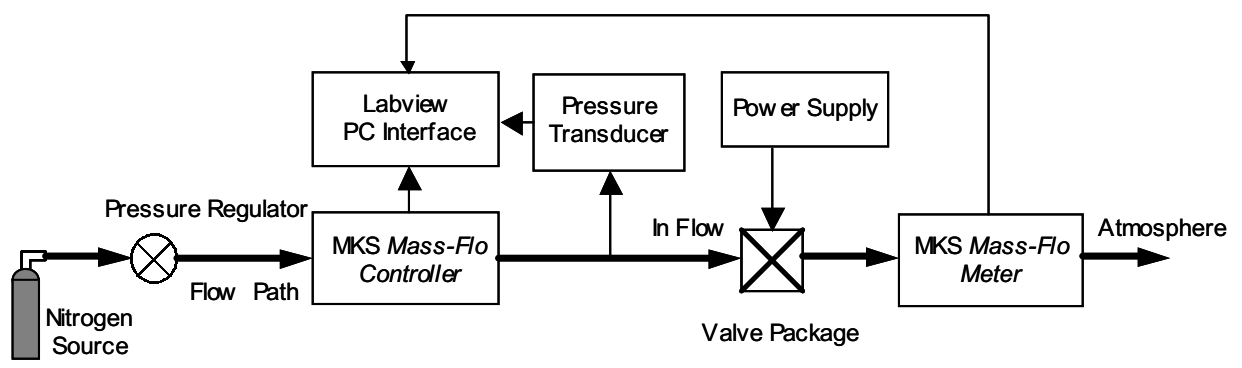

Figure 6. A chart representation of the flow test setup.

A schematic representation of the flow test setup is shown in Figure 6. A Mass-Flow Controller by MKS Instruments was used to measure the flow rate. A Honeywell pressure transducer was used to measure the upstream pressure. Data acquisition was done via a NI GPIB board and a LabVIEW interface was used for data display. For measuring the leak rate, a helium leak detector was used.

\section{TESTING AND RESULTS}

With no external pressure applied, the experimental quasi-static pull-in voltage of the valve was $38 \pm 2 \mathrm{~V}$, which matched with the calculations. The results following were obtained from a die with $34 \mu \mathrm{m}$ diameter valve seat. For gas supplied at the specific pressures, the steady state flow rate as a function of voltage is plotted in Figure 7, showing pull-in instability at different levels. The voltage that initiated a steady flow rate is the minimum DC voltage required to switch on the valve. This switch-on voltage is plotted against the upstream pressure in Figure 8. The flow rates at such pressures are plotted in Figure 9, which illustrates close match with the results of numerical simulation using FLUENT, confirming that at higher pressure $(>\sim 1.5 \mathrm{~atm})$, the flow chokes at the exit of the valve seat. At $10 \mathrm{~atm}$, the opening voltage was $136 \mathrm{~V}$, resulting in a flow rate of $45 \mathrm{sccm}$, higher than $30 \mathrm{sccm}$ as designed. This is because the valve diameter as fabricated is larger than designed on the mask. Flow rates can be better controlled by considering the undercut effect of DRIE in the mask design.

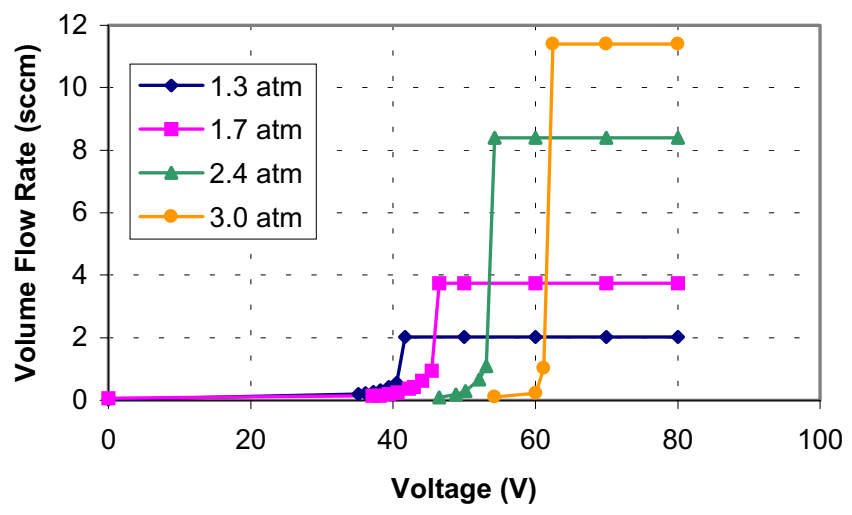

Figure 7. Steady volume flow rate as a function of applied voltage at given pressures.

Leak rates for two dies having different valve seat diameters are plotted in Figure 10. Because of the upper limit of

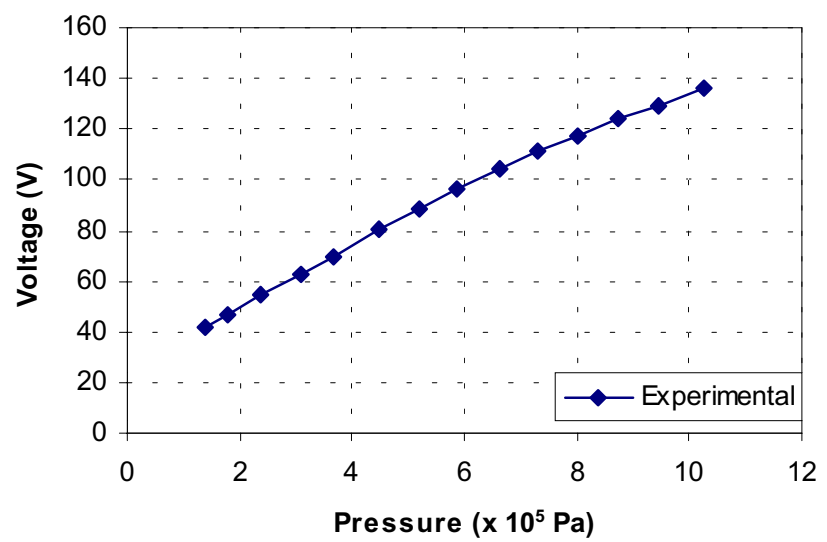

Figure 8. Opening voltage as a function of absolute upstream pressure.

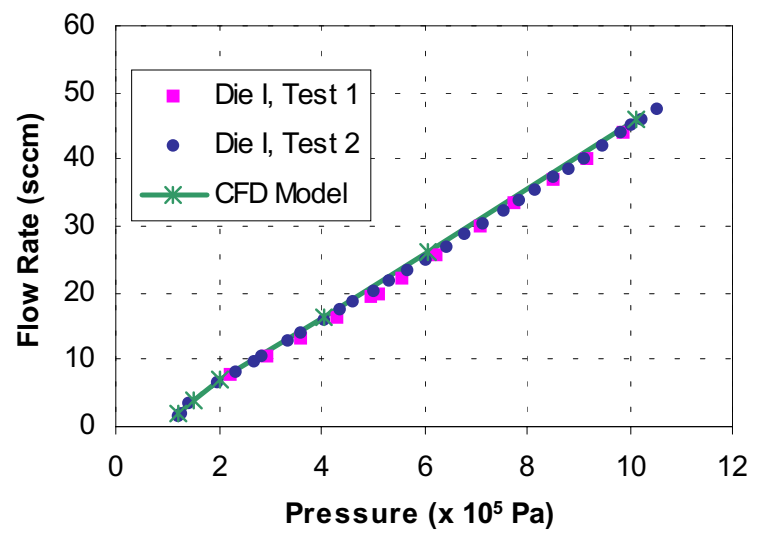

Figure 9. Comparison of steady flow rate vs. absolute upstream pressure with experiment and CFD model.

the detector, leak rates at higher upstream pressure were not available. Using the linear relation as observed from Figure 9, we predicted that the leak rate at $10 \mathrm{~atm}$ upstream pressure would be less than $0.03 \mathrm{sccm}$ for the smaller valve seat case $(34 \mu \mathrm{m}$ diameter). Smaller leak rates were observed with larger valve seats, suggesting that sealing could be improved by altering the valve seat geometry.

A fiber optic sensor was used to detect the motion of the boss during the opening operation (because of the window plate of the flow package, a concave lens had to be used in order to enhance the output signal). At $10 \mathrm{~atm}$, with a step voltage of $136 \mathrm{~V}$, the step response of the valve is shown in Figure 11, 


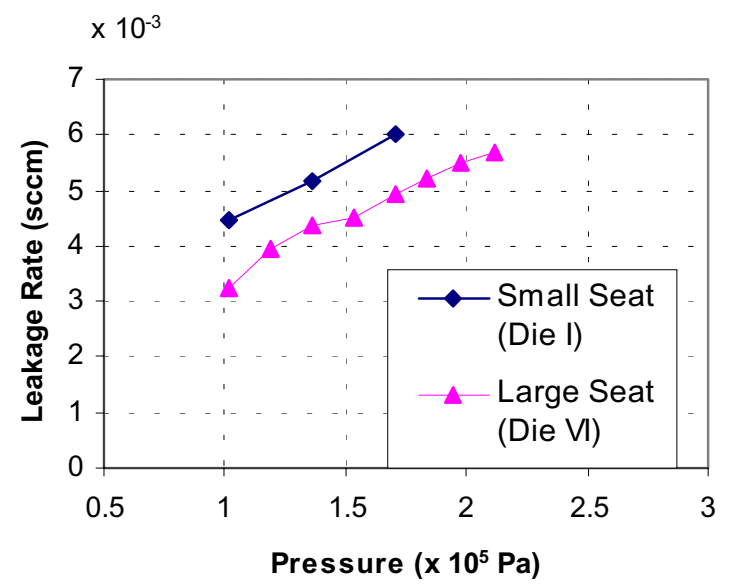

Figure 10. Helium leak rate as a function of the upstream pressure.

revealing a rise time of about $20 \mathrm{~ms}$. Note that oscillations in the plot were caused by the noise in the fiber optic system. The valve was also subjected to cyclic tests using a simulated square waveform. It was demonstrated that at the 10 atm condition, the valve operated without any sign of failure after more than $10^{5}$ cycles.

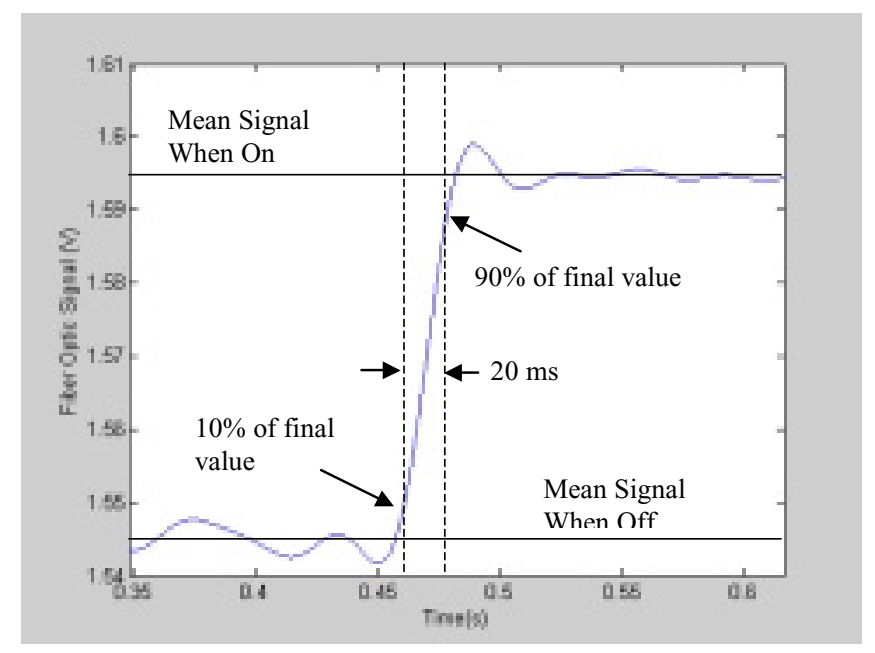

Figure 11. Demonstration of the rise time when the valve was subjected to a step response. The upstream pressure was $10 \mathrm{~atm}$, and the opening voltage was $136 \mathrm{~V}$.

\section{CONCLUSIONS AND FUTURE WORK}

The MIT microengine prototype valve has been fabricated, assembled, and tested. The valve employs electrostatic actuation and uses polysilicon as the valve seat. Design of the valve is made possible using SOI wafers and the DRIE process. The valve has been tested with nitrogen under room temperature. Results demonstrated feasibility of the design of a MEMS valve for the micro gas turbine engine.

In order to modulate the flow and accomplish the control scheme, an array of such valves (designed to be 20) will need to be incorporated into the microengine in the future. Operation at high temperature must also be demonstrated.

\section{ACKNOWLEDGEMENTS}

This work was supported by DARPA TTO, Dr R. Rosenfield manager. The authors would like to thank Prof. A. Epstein, Prof. J. Lang, Dr. A. Ayon, Dr. S. Jacobson, and Dr. S. Umans for their contributions. Travel support has been generously provided by the Transducers Research Foundation and by the DARPA MEMS and DARPA bioflips programs.

\section{REFERENCES}

1. A. H. Epstein et al., "Micro-Heat Engine, Gas Turbine, and Rocket Engines - The MIT Microengine Project", AIAA 97-1773, $28^{\text {th }}$ AIAA Fluid Dynamics Conference, Snowmass Village, CO, June 1997.

2. A. R. Collin, D. W. Kensall, "A ThermopneumaticallyActuated Microvalve with Improved Thermal Efficiency and Integrated State Sensing", Solid-State Sensor and Actuator Workshop, Hilton Head Island, South Carolina, June 4-8, 2000, pp. 234-237.

3. D. J. Sadler, W. O. Kwang, H. A. Chong, et al, "A New Magnetically Actuated Microvalve for Liquid and Gas Control Applications", Transducers'99, June 7-10, 1999, Sendai, Japan, pp. $1812-1815$

4. W. C. Chakraborty, D. P. Bame, T. K. Tang, "MEMS MicroValve for Space Applications", Transducers'99, June 7-10, 1999, Sendai, Japan, pp. 1820-1823

5. K, Sato, et al, "An Electrostatically Actuated Gas Valve with an S-Shaped Film Element", Journal of Micromechanics and Microengineering, 4(1994), pp. 205-209.

6. M. L. Philpott, D. J. Beebe, et al, "Switchable Electrostatic Micro-Valves with High Hold-Off Pressure", Solid-State Sensor and Actuator Workshop, Hilton Head Island, South Carolina, June 4-8, 2000, pp. 226-229.

7. N. Vandelli, D. Wroblewski, M Velonis, T. Bifano, "Development of a MEMS Microvalve Array for Fluid Flow Control”, Journal of Microelectromechanical Systems, Vol. 7, No. 4, December 1998,pp. 395-403.

8. L. Yobas, M. A. Huff, F. J. Lisy, D. M. Durand, "A Novel Bulk-Micromachined Electrostatic Microvalve with a CurvedCompliant Structure Applicable for a Pneumatic Tactile Display", Journal of Microelectro-mechanical Systems, Vol. 10, No. 2, June 2001, pp. 187-196. 